\title{
Association between an arachnoid cyst and intracranial aneurysms misdiagnosed as a cystic tumor with a mural nodule
}

\author{
Case report and review of the literature
}

\author{
Vaninder S. Chhabra, M.D., Jonathan Zhang, M.D., and Jeffery J. Olson, M.D. \\ Department of Neurological Surgery, Emory University School of Medicine, Atlanta, Georgia
}

\begin{abstract}
$\checkmark$ The authors report on a 63-year-old man initially admitted to an outside hospital for altered mental status and respiratory distress. A head computed tomography scan disclosed a right frontal cystic mass, suspected to be a neoplasm. An open biopsy was performed at an outside institution, and on visualization of the cyst, an aneurysm was found incidentally. Postoperatively, an angiogram and magnetic resonance image confirmed the presence of a distal right $\mathbf{M}_{1}$ segment aneurysm. The patient was transferred to our institution where, in addition to the middle cerebral artery lesion, a right anterior choroidal artery aneurysm was found intraoperatively; the necks of both aneurysms were clipped successfully. A review of the literature revealed 14 additional cases of intracranial aneurysms associated with arachnoid cysts. Data in the present report highlight the importance of considering an intracystic aneurysm in the differential diagnosis when reviewing cases that involve a cystic mass with a mural nodule. The authors provide a comprehensive summary of documented cases of aneurysms associated with arachnoid cysts. In addition, they include a discussion of prevailing thoughts on the origin and evolution of arachnoid cysts.
\end{abstract}

KEY WORDS • aneurysm • arachnoid cyst - craniotomy • mural nodule

I N GENERAL, when CT scans reveal a cystic mass with a mural nodule, a malignant glioma or other tumor is highly suspected. ${ }^{1}$ There have been sporadic reports of arachnoid cysts associated with aneurysms resembling a cystic mass with a mural nodule, but no review in which these findings are summarized. Arachnoid cysts have been previously associated with chronic subdural hematomas $2,9,11,18,30$ and less frequently with aneurysms. More arachnoid cysts are being diagnosed given the increased frequency of neuroimaging procedures. On neuroimages, these lesions appear as smooth-bordered, noncalcified, extraparenchymal cystic masses with a density similar to CSF and no enhancement with the intravenous administration of contrast material. They can cause expansion and remodeling of nearby bone, which typically depicts its chronic nature. . $10,28,30$ Most occur in the anterior half of the middle cranial fossa. ${ }^{3}$

An arachnoid cyst is a leptomeningeal cyst, perhaps congenital, forming from the splitting of arachnoid membranes. It can be categorized as primary or secondary. Primary arachnoid cysts are developmental abnormalities, whereas secondary arachnoid cysts can result from trauma, infection, surgery, or previous hemorrhage..$^{7,915}$ A number of hypotheses have evolved regarding the origins of

Abbreviations used in this paper: $\mathrm{ACA}=$ anterior cerebral artery; $\mathrm{AChA}=$ anterior choroidal artery; $\mathrm{CSF}=$ cerebrospinal fluid; $\mathrm{CT}=$ computed tomography; $\mathrm{MCA}=$ middle cerebral artery; $\mathrm{MR}=$ magnetic resonance; $\mathrm{SAH}=$ subarachnoid hemorrhage. arachnoid cysts and their potential relationship to intracranial aneurysms. Here, we describe a case encountered at our institution and review the literature documenting additional institutional experiences with arachnoid cysts associated with aneurysms.

\section{Case Report}

History. This 63-year-old man, who was initially admitted to an outside hospital for pneumonia, presented with an altered mental status and respiratory distress. A head CT was obtained and disclosed a right frontal cystic mass (Fig. 1). An open biopsy was performed given the suspiciousness of the lesion. On visualization of the cyst, an aneurysm was found incidentally. Postoperatively, an angiogram confirmed the presence of a distal right $\mathrm{M}_{1}$ segment aneurysm (Fig. 2).

Examination. The patient was transferred to our institution, where he arrived neurologically intact. An MR image confirmed the presence of an enhancing right frontal cystic lesion measuring approximately $4 \times 4.8 \times 4.5$ $\mathrm{cm}$ (transaxial $\times$ anteroposterior $\times$ craniocaudal) as well as the distal right MCA aneurysm incorporated along the inferior margin of the lesion (Fig. 3). The cyst itself appeared to contain material consistent with CSF on MR imaging.

Operation. The patient was taken to the operating room and underwent a standard right-sided craniotomy. The 


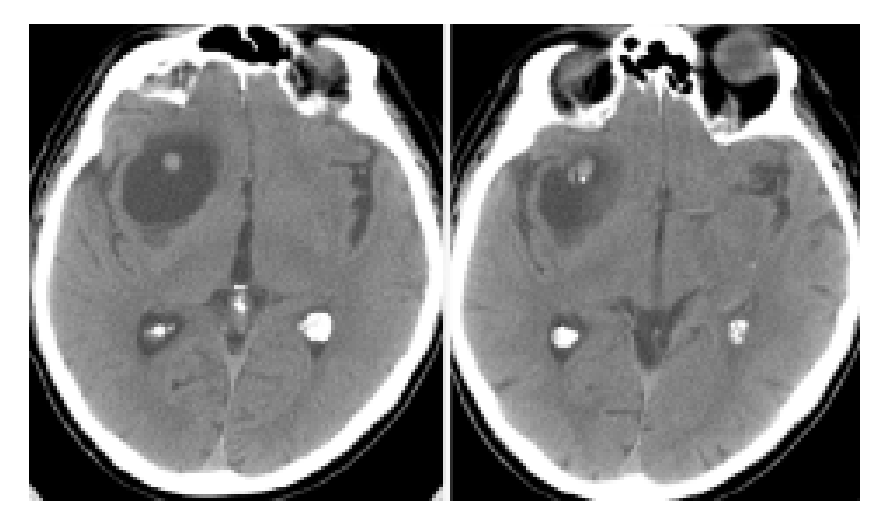

FIG. 1. Left and Right: Axial non-contrast-enhanced CT scans revealing a right frontal cystic mass with an intracystic nodule.

arachnoid cyst was marsupialized and drained. Intraoperative findings revealed clear CSF from within the cyst on decompression. Inferiorly, hemosiderin staining was noted to overlie the dome of the right MCA aneurysm. On further dissection, a right AChA aneurysm was discovered. The necks of both the MCA and AChA aneurysms were clipped using an appropriate microvascular technique. The pathological specimens disclosed reactive gliosis surrounding the cyst. Focal vascular proliferation and chronic inflammation were also noted, suggesting a cyst wall lining.

\section{Discussion}

In a review of the available literature, we found that six of 15 cases reported involved female patients (Table 1). ${ }_{3}^{3,411-14,20,26,31,35}$ Symptoms typically included headache, nausea, and vomiting. Most arachnoid cysts were found in the anterior half of the middle cranial fossa. Six patients had right-sided aneurysms, whereas nine had left-sided ones. Patients in four cases were noted to have multilocular cysts, three of which involved the posterior circulation. Five cases involved MCA aneurysms, and all of the patients in these cases presented with unilocular cysts. Four

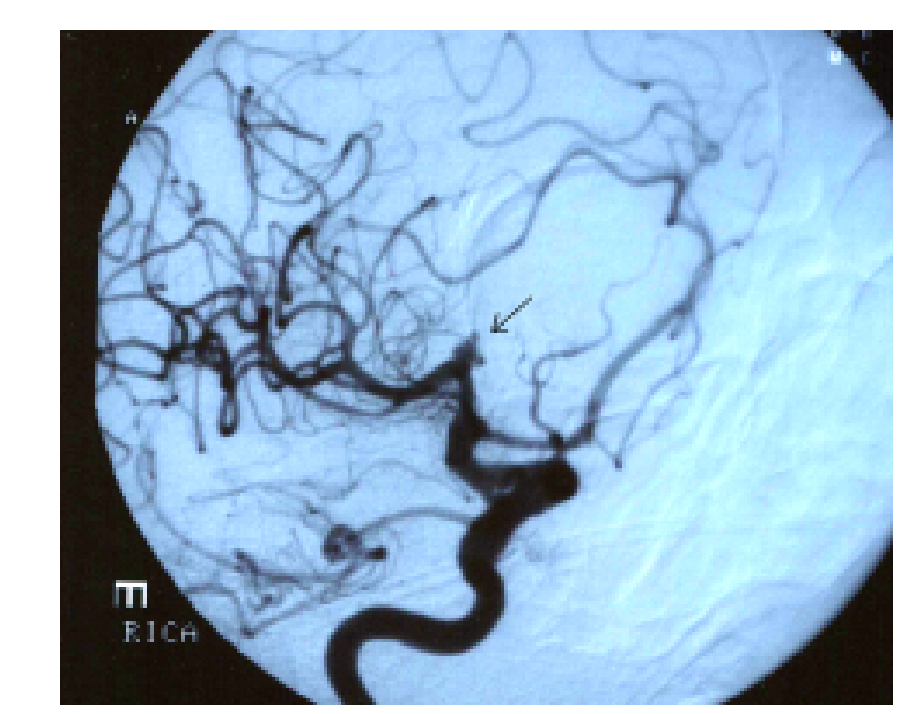

FIG. 2. Transorbital cerebral angiogram revealing a right MCA aneurysm (arrow).

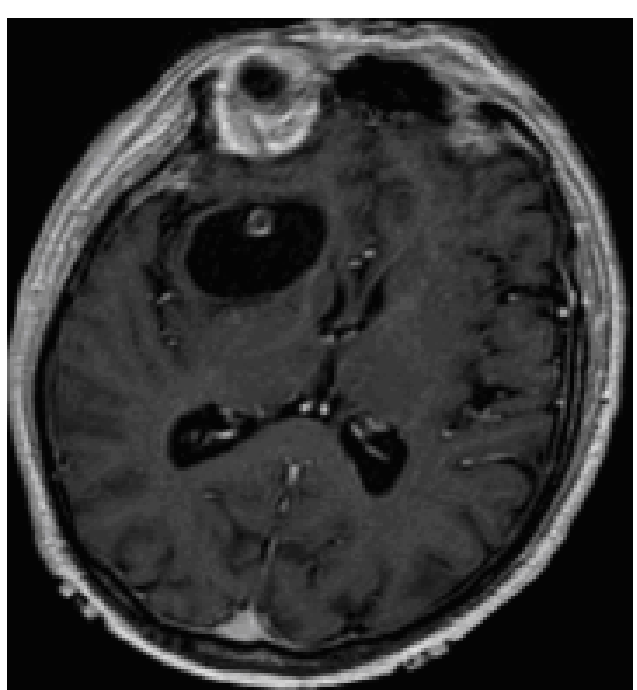

FIG. 3. Contrast-enhanced MR image revealing a right frontal cystic mass with an intracystic enhancing nodule, confirmed to be an MCA aneurysm on angiography.

cases were described as having aneurysmal calcification and/or thromboses, and rupture was not apparent on presentation. In two cases, including the one featured in the present report, a second aneurysm was noted on the same side. ${ }^{11}$ In all documented cases, the dome of the aneurysm always projected toward the cystic space.

Authors of five reports documented the communication between an aneurysm and arachnoid cyst within the context of a recent aneurysm rupture and intracystic hematoma. The arachnoid cyst was located in the middle cranial fossa in 10 cases; four involved an intracystic hematoma and three had xanthochromic fluid. ${ }^{3,4,11,13,14}$ Subarachnoid hemorrhage was present in only three of the 15 cases. Only two cases entailed a subdural hematoma, suggesting a local tear in the arachnoid membrane during aneurysm rupture. ${ }^{4,13}$

Authors of three cases noted xanthochromic fluid on surgically opening the cyst. . $^{12,20,35}$ In the case described by Marcoux et al.,$^{20}$ a cyst had formed 17 months after an SAH and embolization of an ACA aneurysm. These authors ascribed this acquired arachnoid cyst to a postinflammatory process. Two other cases, including the one featured in the present report, demonstrated hemosiderin layering on preoperative MR imaging, suggesting prior hemorrhage. ${ }^{26}$

Starkman et al..$^{30}$ defined arachnoid cysts as closed compartments situated within the arachnoid and segregated from subarachnoid spaces. We propose that the patient in the present case could have experienced a remote episode of SAH with subsequent arachnoiditis and adhesion formation initiating the development of a secondary arachnoid cyst. Given the contrast enhancement and hemosiderin layering at the base of the cyst on MR images and on intraoperative examination, respectively, we admitted that an age-indeterminate SAH or parenchymal hemorrhage might have occurred, disrupting the preexisting subarachnoid membranes. Based on our review, once an arachnoid cyst has formed, an intracystic aneurysm rupture is likely to appear initially as an intracystic hematoma, with fewer instances of acute SAH. 


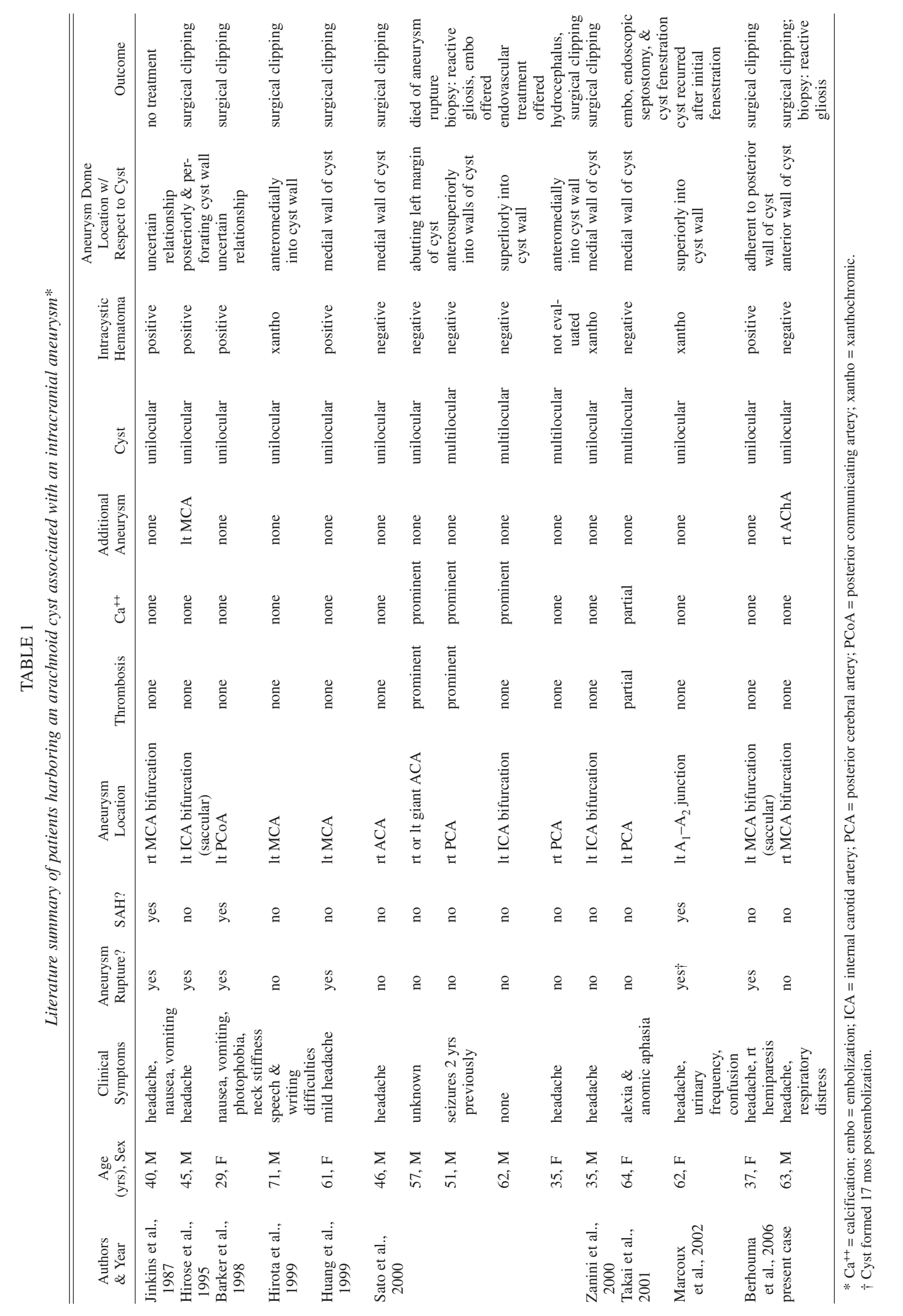


With the presence of hemolyzed blood in the subarachnoid spaces, a cascade of events occurs, creating a fibroproliferative reaction that results in arachnoiditis. Data from molecular studies have shown that the increase in procollagen propeptides found in the CSF after SAH can be correlated with the increased rate of meningeal collagen synthesis. ${ }^{22-24} \mathrm{~A}$ number of authors have documented the formation of spinal arachnoiditis and an arachnoid cyst after SAH, particularly those involving posterior fossa circulation aneurysms. ${ }^{16,19,32}$

Sato et al. ${ }^{26}$ have also described a case that supports the concept of cyst formation following parenchymal hemorrhage. Three additional cases have entailed xanthochromic fluid on opening the arachnoid cyst, again suggesting a previous SAH..$^{12,20,35}$ Interestingly, all documented cases have involved an aneurysm dome projecting toward the cystic space. In particular, five cases involved aneurysm rupture and intracystic hematoma. These examples also suggest a previous SAH event that initiated a postinflammatory cascade, creating a cystic cavity.

Fox and Al-Mefty ${ }^{8}$ described a pediatric case with a history of head trauma. The initial cyst origin was an outpouching of an imperforate membrane of Liliequist by a previous hemorrhage, infection, or maldevelopment. These authors hypothesized that the cysts begin as diverticulae of the membrane of Liliequist, allowing the entrance of CSF. The fibroproliferative reaction involving the multiple layers of the membrane of Liliequist may likely explain the predominant multilocular nature of cysts involving posterior circulation aneurysms noted in our review. Sato and colleagues ${ }^{26}$ have suggested that arachnoid cysts evolve from exudation or edema induced by vascular endothelial growth factor, a premise similar to theories regarding cyst formation in tumors. ${ }^{29}$

Krawchenko and Collins ${ }^{17}$ have described a ball-valve action between the cyst and subarachnoid space with the possible association of an osmotic gradient as one potential mechanism for arachnoid cyst enlargement. ${ }^{25}$ Some authors have suggested that a valve action exists only in traumatic cysts; however, endoscopic observations reveal that congenital cysts can also expand by this mechanism. ${ }^{6,17}$ Williams and Guthkelch ${ }^{34}$ have posited that arachnoid cyst enlargement involves a pulsatile pump mechanism driven by transient pressure gradients established by the responsiveness of the subarachnoid space to changes in venous pressure. ${ }^{25}$ Santamarta and colleagues ${ }^{25}$ have used cine phase-contrast MR imaging to support the theory of a pressure gradient between the subarachnoid space and the cyst that would operate like a one-way valve. They have suggested that the gradient is sustained by expansion of the brain during arterial inflow, ${ }^{7,21}$ as has been shown in previous measurements obtained using cine phase-contrast MR imaging. ${ }^{5,6,25,27}$

Its nodular appearance on CT or MR images means that an aneurysm can be mistaken for a mural nodule when surrounded by a cystic mass. Key to making a correct diagnosis is an understanding of the vascular anatomy in the immediate vicinity of the nodule. The case in the present report clearly highlights its association with the distal $\mathrm{M}_{1}$ segment. In addition to our case, there have been other documented cases suspected to be a cystic neoplasm. ${ }^{1,26,33}$ Our pathological results coincide with the documented findings of Sato et al., ${ }^{26}$ in that they are consistent with mild reactive gliosis without evidence of hemorrhage. Oversight of an aneurysm when performing resection or biopsy of a cystic mass with a mural nodule can lead to unanticipated aneurysm rupture. The gravity of such an error could explain the paucity of such cases in the literature.

\section{Conclusions}

The featured case marks the importance of considering the presence of an aneurysm in the differential diagnosis of a cystic mass with a mural nodule. Given that only 15 cases of aneurysms with associated arachnoid cysts have been described in the literature, much more investigation is necessary. Additional studies in which authors use cine MR imaging and endoscopy will reveal the potential origins of such interesting pathophysiology. Having a precipitant SAH may play a greater role in the development of arachnoid cysts than previously noted. Because aneurysmal SAHs are being diagnosed and treated more frequently, we will continue to gather more information regarding this interesting phenomenon.

\section{References}

1. Afra D, Norman D, Levin VA: Cysts in malignant gliomas. Identification by computerized tomography. J Neurosurg 53: $821-825,1980$

2. Auer LM, Gallhofer B, Ladurner G, Sager WD, Heppner F, Lechner H: Diagnosis and treatment of middle fossa arachnoid cysts and subdural hematomas. J Neurosurg 54:366-369, 1981

3. Barker RA, Phillips RR, Moseley IF, Taylor, WJ, Kitchen ND, Scadding JW: Posterior communicating artery aneurysm presenting with haemorrhage into an arachnoid cyst. J Neurol Neurosurg Psychiatry 64:558-560, 1998

4. Berhouma M, Jemel H, Khaldi M: [Aneurysm rupture into an arachnoid cyst of the middle cranial fossa.] J Neuroradiol 33:206-207, 2006 (Fr)

5. Caemaert J, Abdullah J, Calliauw L, Carton D, Dhooge C, van Coster R: Endoscopic treatment of suprasellar arachnoid cysts. Acta Neurochir (Wien) 119:68-73, 1992

6. Choi JU, Kim DS: Pathogenesis of arachnoid cyst: congenital or traumatic? Pediatr Neurosurg 29:260-266, 1998

7. Enzmann DR, Pelc NJ: Cerebrospinal fluid flow measured by phase-contrast cine MR. AJNR Am J Neuroradiol 14: 1301-1310, 1993

8. Fox JL, Al-Mefty O: Suprasellar arachnoid cysts: an extension of the membrane of Liliequist. Neurosurgery 7:615-618, 1980

9. Giudicelli G, Hassoun J, Choux M, Tonon C: Supratentorial "arachnoia” cysts. J Neuroradiol 9:179-201, 1982

10. Hara H, Inoue T, Matsuo K, Kobayashi S, Sugita K: Unusual computed tomographic findings in a case of arachnoid cyst in the middle cranial fossa. Surg Neurol 22:79-82, 1984

11. Hirose S, Shimada S, Yamaguchi N, Hosotani K, Kawano H, Kubota T: Ruptured aneurysm associated with arachnoid cyst: intracystic hematoma without subarachnoid hemorrhage. Surg Neurol 43:353-356, 1995

12. Hirota N, Ueno J, Naitoh H, Sugiyama K, Karasawa H, Horoshi $\mathrm{K}$, et al: Giant aneurysm associated with a large cyst. Case illustration. J Neurosurg 91:160, 1999

13. Huang D, Abe T, Kojima K, Tanaka N, Watauabe M, Ohkura A, et al: Intracystic hemorrhage of the middle fossa arachnoid cyst and subdural hematoma caused by ruptured middle cerebral artery aneurysm. AJNR Am J Neuroradiol 20: 1284-1286, 1999

14. Jinkins JR, Siqueira EB, Holoubi A: Ruptured middle cerebral 
aneurysm with accumulation of subarachnoid blood within convexity arachnoid cyst. Comput Radiol 11:185-187, 1987

15. Kadson DL, Douglas EA, Brougham MF: Suprasellar arachnoid cyst diagnosed preoperatively by computerized tomographic scanning. Surg Neurol 7:299-303, 1977

16. Kok AJ, Verhagen WI, Bartels RH, van Dijk R, Prick MJ: Spinal arachnoiditis following subarachnoid haemorrhage: report of two cases and review of the literature. Acta Neurochir (Wein) 142:795-799, 2000

17. Krawchenko J, Collins GH: Pathology of an arachnoid cyst. Case report. J Neurosurg 50:224-228, 1979

18. Leo JS, Pinto RS, Hulvat GF, Epstein F, Kricheff II: Computed tomography of arachnoid cysts. Radiology 130:675-680, 1979

19. Lorenzana-Honrado L, Cabezudo-Artero JM, Gozez-Perals L: Arachnoid cyst. J Neurosurg 85:734-735, 1996 (Letter)

20. Marcoux J, Roy D, Bojanowksi MW: Acquired arachnoid cyst after a coil-ruptured aneurysm. Case illustration. J Neurosurg 97:722, 2002

21. Naidich TP, Altman NR, Gonzales-Arias SM: Phase contrast cine magnetic resonance imaging: normal cerebrospinal fluid oscillation and applications to hydrocephalus. Neurosurg Clin N Am 4:677-705, 1993

22. Sajanti J, Heikkinen E, Majamaa K: Rapid induction of meningeal collagen synthesis in the cerebral cisternal and ventricular compartments after subarachnoid hemorrhage. Acta Neurochir (Wien) 143:821-826, 2001

23. Sajanti J, Heikkinen E, Majamaa K: Transient increase in procollagen propeptides in the CSF after subarachnoid hemorrhage. Neurology 55:359-363, 2000

24. Sajanti J, Majamaa K: Detection of meningeal fibrosis after subarachnoid haemorrhage by assaying procollagen propeptides in cerebrospinal fluid. J Neurol Neurosurg Psychiatry 67:185-188, 1999

25. Santamarta D, Aguas J, Ferrer E: The natural history of arachnoid cysts: endoscopic and cine-mode MRI evidence of a slitvalve mechanism. Minim Invasive Neurosurg 38:133-137, 1995

26. Sato N, Sze G, Awad IA, Putman CM, Shibazaki T, Endo K:
Parenchymal perianeurysmal cystic changes in the brain: report of five cases. Radiology 215:229-233, 2000

27. Schroeder HWS, Gaab MR: Endoscopic observation of a slitvalve mechanism in a suprasellar prepontine arachnoid cyst: case report. Neurosurgery 40:198-200, 1997

28. Shaw CM: 'Arachnoid cysts' of the sylvian fissure versus "temporal lobe agenesis" syndrome. Ann Neurol 5:483-485, 1979

29. Skirgaudas M, Awad IA, Kim J, Rothbart D, Criscuolo G: Expression of angiogenesis factors and selected vascular wall matrix proteins in intracranial saccular aneurysms. Neurosurgery 39:537-547, 1996

30. Starkman SP, Brown TC, Linell EA: Cerebral arachnoid cysts. J Neuropathol Exp Neurol 17:484-500, 1958

31. Takai, K, Nishihara T, Nemoto S, Ueki K, Miyauchi H, Mishima K, et al: Multilocular cystic lesion associated with a giant aneurysm. J Neurosurg 95:1081, 2001

32. Tumialan LM, Cawley CM, Barrow DL: Arachnoid cyst with associated arachnoiditis developing after subarachnoid hemorrhage. Case report. J Neurosurg 103:1088-1091, 2005

33. Verhagen ITHJ, Zeilstra DJ, Go KG: Differential diagnosis of supratentorial cystic intracranial lesions by CT-scanning. Br J Neurosurg 1:447-454, 1987

34. Williams B, Guthkelch AN: Why do central arachnoid pouches expand? J Neurol Neurosurg Psychiatry 37:1085-1092, 1974

35. Zanini MA, Gabarra RC, Faleiros AT, Freitas CC, Alves A: [Cerebral aneurysm and arachnoid cyst: about a case with intracystic hemorrhage.] Arq Neuropsiquiatr 58:330-335, 2000 (Portuguese)

Manuscript submitted November 16, 2006.

Accepted January 8, 2007.

Address reprint requests to: Vaninder S. Chhabra, M.D., Department of Neurological Surgery, Emory University School of Medicine, 1365-B Clifton Road NE, Suite 6200, Atlanta, Georgia 30322. email: vchhabr@emory.edu. 